\title{
Outcome following resective surgery for temporal lobe epilepsy: a prospective follow up study of 102 consecutive cases
}

\author{
R D C Elwes, G Dunn, C D Binnie, C E Polkey
}

\begin{abstract}
The long term outcome has been assessed in a consecutive series of 102 cases undergoing resective temporal lobe surgery because of medically intractable epilepsy. Patients were followed prospectively for a median of 61 months. Actuarial statistics were used to measure the temporal patterns of remission and stability of outcome over prolonged periods of observation. The probability of achieving one year remission was $\mathbf{5 7 \%}$ by one year, $70 \%$ by two years, and $77 \%$ by seven years. Once a patient was in one year remission the probability of remaining seizure free was $90 \%$. This rose to $94 \%$ after two consecutive years of being seizure free. The majority of patients who remit following surgery have done so by two years of follow up. Outcome at the end of the second post operative year is a good predictor of long term prognosis.
\end{abstract}

Resective temporal lobe surgery can be a highly effective method of treating appropriately selected patients with drug resistant epilepsy. The results of published surgical series containing 50 or more patients are summarised in table 1 . The method of reporting results have broadly followed the classification of outcome initially proposed by Penfield, ${ }^{1}$ although different centres have introduced variations that make the precise comparison of results difficult. Patients who are seizure free (group 1) or experience only occasional attacks (group 2), are usually con- sidered to have had a successful postoperative outcome. Using these criteria between 50$60 \%$ of patients in the larger reported series do well following surgery. Those centres reporting consecutive series have generally shown better results in more recent reports. ${ }^{10}$ About one fifth of patients do not improve following surgery.

Engel $^{10}$ has recently published a critical review of previous prognostic studies. He emphasised that patterns of seizure control may vary over prolonged periods of follow up. Some patients experience seizures in the postoperative period but these then run down and are followed by a prolonged period of remission. Conversely, others are seizure free but then suffer a relapse, sometimes reverting to their original seizure frequency. ${ }^{6}$ Engel reported that almost a quarter of patients who were seizure free following surgery had to be classified as having no improvement after 10 years of follow up. On the other hand among patients who had many seizures during the first postoperative year, $38 \%$ had been seizure free for at least two years by the fifth year of follow up.

Changing patterns of seizure control following epilepsy surgery are of considerable importance, yet this subject has received only scant attention in the literature. We have analysed the long term prognosis in a consecutive series of 102 patients undergoing resective surgery for intractable temporal lobe epilepsy. The patients have now been followed prospectively for periods of up to a decade. Actuarial statistics have been used to assess the temporal patterns of remission and the stability of outcome over prolonged periods of observation.

The Institute of
Psychiatry and the
Maudsley Hospital, De
Crespigny Park,
London, UK
Department of
Clinical
Neurophysiology
R D C Elwes
C D Binnie
Department of
Biostatistics and
Computing
G Dunn
Department of
Neurosurgery
C E Polkey
Correspondence to:
Dr Elwes, Department of
Clinical Neurophysiology.
The Maudsley Hospital,
Denmark Hill, London SE5
9RS, UK.
Received 24 October 1990
and in revised form
5 April 1991.
Accepted 24 April 1991

Table 1 Prognostic studies of outcome following resective surgery for non tumoural temporal lobe epilepsy

\begin{tabular}{|c|c|c|c|c|c|c|}
\hline Author & $\begin{array}{l}\text { Date } \\
\text { of } \\
\text { series }\end{array}$ & $\begin{array}{l}\text { Number } \\
\text { of } \\
\text { patients }\end{array}$ & $\begin{array}{l}\text { Seizure } \\
\text { free } \\
N(\%)\end{array}$ & $\begin{array}{l}\text { Occasional } \\
\text { seizure } \\
N(\%)\end{array}$ & $\begin{array}{l}\text { Improved } \\
N(\%)\end{array}$ & $\begin{array}{l}\text { No } \\
\text { change } \\
N(\%)\end{array}$ \\
\hline $\begin{array}{l}\text { Montreal Neurological Institute Series } \\
\text { Penfield \& Flanigin }(1950)^{1} \\
\text { Rasmussen }(1975)^{2} \\
\text { Rasmussen }(1983)^{3}\end{array}$ & $\begin{array}{l}1928-1944 \\
1928-1972 \\
1928-1980\end{array}$ & $\begin{array}{r}51 \\
653 \\
894\end{array}$ & $\begin{array}{r}14(28) \\
257(39) \\
332(37)\end{array}$ & $\begin{array}{r}13(25) \\
69(11) \\
236(26)\end{array}$ & $\begin{array}{l}13(25) \\
140(21) \\
326(37)^{*}\end{array}$ & $\begin{array}{r}11(22) \\
187(27) \\
-\end{array}$ \\
\hline $\begin{array}{l}\text { Maudsley Hospital Series } \\
\text { Falconer and Serafetinedes }(1963)^{4} \\
\text { Current series }^{\mathrm{b}}\end{array}$ & $\begin{array}{l}1950-1960 \\
1976-1987\end{array}$ & $\begin{array}{l}100 \\
102\end{array}$ & $\begin{array}{l}39(39) \\
47(46)\end{array}$ & $\begin{array}{l}14(14) \\
19(19)\end{array}$ & $30(30)$ & $\begin{array}{l}17(17) \\
36(35)\end{array}$ \\
\hline $\begin{array}{l}\text { Green \& Scheetz }(1964)^{5} \\
\text { Van Buren et al }(1975)^{6} \\
\text { Jensen }(1975)^{7} \\
\text { Bonis }(1980)^{8} \\
\text { Dodrill et al }(1985)^{9}\end{array}$ & $\begin{array}{l}1948-1961 \\
1954-1969 \\
1960-1969 \\
1960-1975 \\
1973-1983\end{array}$ & $\begin{array}{r}60 \\
124 \\
74 \\
104 \\
100\end{array}$ & $\begin{array}{l}12(20) \\
26(21) \\
45(61) \\
67(64) \\
40(40)\end{array}$ & $\begin{array}{l}13(21) \\
41(33) \\
= \\
=\end{array}$ & $\begin{array}{l}16(27) \\
16(13) \\
15(20) \\
23(22) \\
26(26)\end{array}$ & $\begin{array}{l}19(32) \\
41(33) \\
14(19) \\
14(14) \\
34(34)\end{array}$ \\
\hline
\end{tabular}

$a=$ Contains an unstated number who were not improved

$b=$ Using similar methods of analysis as Falconer and Serafetinides

$c=$ Results relate to outcome during the second postoperative year.

Improved group contains an unstated number of patients with occasional seizures. 


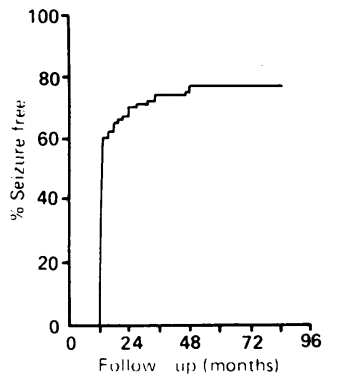

Figure The cumulative percentage of patients achieving one year remission by duration of follow up.
Patients and methods

Between March 1976 and March 1987, 108 consecutive patients had "en bloc" anterior temporal lobectomy at the Maudsley Hospital because of medically intractable epilepsy. All patients had interictal routine, sleep and pentothal-sphenoidal EEG recordings. If the site of origin of seizures was unresolved ictal recordings with video telemetry and occasionally bilateral subdural strip electrodes were used. Comprehensive IQ assessment with the Wechsler Adult Intelligence Scale and also the Wechsler and Rey-Osterreith memory tests were used and where needed carotidamytal testing. All patients had pneumoencephalography or CT brain scan. Patients were seen at six months to yearly intervals in the outpatient department. At each visit the total number, and where possible, dates of individual seizures were recorded. Data were inadequate in five patients, four of whom were lost to follow up. One patient died in the immediate postoperative period. The results are based on the remaining 102 patients who were followed prospectively for a median of 61 months, range 8 to 144 months (see table 2). Five patients died during follow up, two of whom asphyxiated during a seizure and one patient died during status epilepticus following alcohol abuse. One patient committed suicide and the last case was seizure free and died in a road traffic accident. In assessing outcome all data have been included up to the time of death or last follow up visit.

Seizures occurring in the first postoperative week (so called "neighbourhood fits"4) were excluded. In accordance with previous reports ${ }^{34}$ patients who experienced only auras, defined as short-lived premonitory symptoms with no disturbance of cognitive or motor function, were considered to be seizure free. Each month of follow up was coded as being either fit-free or not. At the end of each year of follow up patients were classified into three groups (or states) using the following criteria: 1) Seizure free: no seizures in the previous 12 months; 2) Occasional seizures: between one and three months inclusive in the year in which seizures were recorded; 3) Poor response: between four and 12 months in the previous year in which seizures were recorded. Survival curves using Kaplan-Meier estimates ${ }^{11}$ were used to measure the actuarial percentage of patients achieving one year remission. All statistical analyses were carried out using SPSS-PC version 3.12

\section{Results}

Seizure control at the end of follow up

Of the 101 cases who were followed for more

Table 3 Outcome following temporal lobe surgery. The percentage of patients seizure free, experiencing occasional seizures or with a poor response by each year of follow up

\begin{tabular}{lllll}
\hline $\begin{array}{l}\text { Year of } \\
\text { follow up }\end{array}$ & $\begin{array}{l}\text { Number of } \\
\text { patients }\end{array}$ & $\begin{array}{l}\text { Seizure } \\
\text { free \% }\end{array}$ & $\begin{array}{l}\text { Occasional } \\
\text { seizures (\%) }\end{array}$ & $\begin{array}{l}\text { Poor } \\
\text { response \% }\end{array}$ \\
\hline 1 & 101 & 56 & 21 & 23 \\
2 & 100 & 60 & 14 & 26 \\
3 & 94 & 57 & 15 & 28 \\
4 & 77 & 61 & 16 & 23 \\
5 & 69 & 67 & 16 & 17 \\
6 & 52 & 57 & 24 & 19 \\
\hline
\end{tabular}

Table 2 Clinical characteristics, temporal lobe pathology and follow up intervals in 102 patients undergoing resective temporal lobe surgery

\begin{tabular}{ll}
\hline & $\begin{array}{l}\text { Number of } \\
\text { patients }\end{array}$ \\
\hline Male & 54 \\
Female & 48 \\
Median age (range) & $23(3-53)$ \\
Side of operation & \\
Left & 49 \\
Right & 53 \\
Temporal lobe pathology & \\
Mesial temporal sclerosis & 58 \\
Tumour (a) & 14 \\
Non specific & 10 \\
Harmatoma & 4 \\
Arterio-venous malformation & 3 \\
Cortical dysplasia & 1 \\
Other & 12 \\
Postoperative follow-up & \\
<24 months & 2 \\
24-47 months & 23 \\
48-71 months & 25 \\
72-95 months & 27 \\
>95 months & 25 \\
Median follow up, months (range) & 61 (8-144) \\
\hline
\end{tabular}

(a) not apparent preoperatively

than a year 64 were seizure free and had experienced no attacks for a mean duration of 59 months, range 19 to 122 months. Twenty of the patients who were seizure free had successfully stopped antiepileptic medication. Eleven patients were experiencing occasional attacks and the remaining 26 patients had poor seizure control.

\section{Temporal Pattern of Remission}

The temporal pattern of remission in relation to duration of follow up was measured using actuarial statistics (fig). By 12 months postoperatively $57 \%$ of patients had achieved a one year remission, $65 \%$ by 18 months, $70 \%$ by 24 months, $74 \%$ by 36 months and $77 \%$ by five, six and seven years of follow up. Ninety per cent of patients who had a remission did so within two years of surgery.

\section{Stability of Outcome}

The percentage of patients who were either seizure free; experiencing occasional attacks or who had a poor response following surgery by each consecutive year of follow up is shown in table 3. Although the percentages in each group remained stable after the first year of follow up it was apparent that transfers between the groups could occur. Some patients who were experiencing seizures postoperatively subsequently remitted whilst others relapsed following a period of satisfactory control. The probability of transfer between each of the three states was calculated based on the total number of transitions for the whole period of follow up. Patients who were seizure free at the end of any year of follow up had a $90 \%$ probability of having no further seizures in the next year of follow up, a 9\% chance of developing occasional seizures and $1 \%$ probability of relapsing with poor seizure control. Patients who were experiencing occasional seizures had a $40 \%$ probability of remaining in this state, a $42 \%$ chance of becoming seizure-free and an $18 \%$ probability of relapsing with worsening seizure control. Patients who had an unsatisfactory response at any time following surgery had an $86 \%$ probability of continuing to have 
Table 4 Final outcome in 94 patients compared with response at the end of the second postoperative year

\begin{tabular}{|c|c|c|c|c|}
\hline \multirow[b]{2}{*}{$\begin{array}{l}\text { Seizure control at end of } \\
\text { second post-operative year }\end{array}$} & \multirow[b]{2}{*}{$\begin{array}{l}\text { Median duration } \\
\text { of follow-up } \\
\text { months (range) }\end{array}$} & \multicolumn{3}{|c|}{ Seizure control status at end of follow up } \\
\hline & & $\begin{array}{l}\text { Seizure } \\
\text { free } \\
N(\%)\end{array}$ & $\begin{array}{l}\text { Occasional } \\
\text { seizures } \\
N(\%)\end{array}$ & $\begin{array}{l}\text { Poor } \\
\text { response } \\
N(\%)\end{array}$ \\
\hline $\begin{array}{l}\text { Patient seizure free }(N=58) \\
\text { Patients with occasional seizures }(N=13) \\
\text { Patients with poor control }(N=23)\end{array}$ & $\begin{array}{l}41 \cdot 5(1-120) \\
38(1-83) \\
31(1-72)\end{array}$ & $\begin{array}{r}52(90) \\
8(62) \\
3(13)\end{array}$ & $\begin{array}{l}6(10) \\
2(15) \\
7(30)\end{array}$ & $\begin{array}{l}- \\
3(23) \\
13(57)\end{array}$ \\
\hline
\end{tabular}

seizures, an $8 \%$ chance of developing occasional seizures and a $6 \%$ probability of becoming seizure free. These transition probabilities were slightly pessimistic for those patients who were fit-free at the beginning of the follow up year and slightly too optimistic for those who were still having frequent seizures. For patients who had two successive years seizure free, the probability of staying seizure free in the third year was $94 \%$. Conversely, the probability of a patient continuing to have frequent seizures given two previous successive years of poor outcome was estimated to be $90 \%$.

The final outcome for all the patients compared with their response at the end of the second postoperative year is shown in table 4 . These data are based upon 94 cases in whom further follow up was available. Of the 58 patients who were seizure free, 52 were still in this state after a median follow up of 41.5 months. Six patients had relapsed and were experiencing occasional attacks. In three cases these were isolated events consisting of one or two seizures. Only three patients were experiencing attacks in each consecutive year of follow up. No patient who was seizure free two years postoperatively was classified as having a poor outcome at the end of follow up. There was a tendency for seizures to decrease among the 23 cases who had a poor response two years following surgery. Seven had occasional attacks and three became seizure free by the end of the follow up. The pattern of seizure control was less stable for the small group of patients experiencing occasional seizures, two thirds of whom became seizure free.

\section{Discussion}

An important aspect of assessing outcome following epilepsy surgery is that patterns of seizure control can vary over time. Some patients experience seizures in the post operative period but these may decrease and be followed by a prolonged period of remission. At the end of the first postoperative year $57 \%$ of patients had achieved a one year remission and $70 \%$ after two years. Thereafter, a further $7 \%$ of cases remitted over the next five years of follow up. Once a patient had achieved a one year remission the subsequent outlook was good. On average the probability of remaining seizure free during the next year of follow up was $90 \%$. This rose to $94 \%$ if a patient had been two consecutive years free of seizures. Relapses, when they occurred, were usually isolated events of one or two seizures. Of the 58 patients who were seizure free at the end of the second postoperative year 52 were still in this state at the end of follow up. No patient had relapsed at the end of follow up with an intractable seizure disorder. This group of patients were followed for a median period of six years from the time of surgery and it is unlikely that a significant proportion of cases would have to be classified as having had a poor outcome on further follow up. Patients who were likely to have a poor prognosis could also be identified with a reasonable degree of certainty in the early postoperative period. A considerable degree of variability in outcome was seen, however, in cases classified as having occasional seizures. In this group of patients the probability of becoming seizure free was $42 \%$ and of relapsing with poor control was $18 \%$.

It is difficult to compare these results with other surgical series because of varying definitions of seizure control. Falconer and Serafetinides $^{4}$ reported that patients had a successful outcome if they were seizure free after the first postoperative year (39\% of cases) or had only occasional attacks, defined as not more than three seizures in any year $(14 \%$ of cases). Using the same method of analysis the comparative results for this series were $46 \%$ and $19 \%$ respectively (see table 1 ). A more complex method has been used to analyse the outcome in the 894 patients having resective surgery for non tumoural temporal lobe epilepsy at the Montreal Neurological Institute between 1928-60. ${ }^{3}$ Patients who were completely seizure free since discharge from hospital (22\% of cases), became seizure free after some early attacks ( $15 \%$ of cases), had been fit free for three or more years at any time $(13 \%)$ or who averaged not more than two seizures a year $(13 \%)$ were considered to have had a good result. Using this definition the total of successfully operated cases was $63 \%$ compared with $71 \%$ for the present series. Engel ${ }^{10}$ in a survey of 2336 patients operated upon in $\mathbf{4 0}$ centres defined seizure free as at least two years with no attacks, regardless of duration of follow up. The percentages of these that were seizure free in different centres ranged from $26 \%$ to $80 \%$ with a mean of $55.5 \%$. In this series $61 \%$ of patients were seizure free after a median follow up of five years.

It is apparent that a uniform method of reporting the results of surgical series is needed. Epilepsy surgery is a rapidly advancing field and a reliable method of assessing the impact of new methods of presurgical evaluation and new surgical techniques is urgently needed. Most authors have used a system of classifying outcome similar to that initially proposed by Penfield ${ }^{1}$ which divides outcome into four main groups (see table 1). There are, 
however, a number of difficulties with this classification. Patients who experience occasional seizures or who are "almost seizure free" (group 2 in table 1) may indeed have benefited from surgery. However, as we and others $^{610}$ have shown, this group is of very limited prognostic value as few patients remain in this state for any appreciable period of time. About one quarter of cases will relapse with worsening seizure control and two thirds become seizure free. Attempts to define a group of patients who, if not seizure free, have at least "improved" following surgery have met with even less success. Definitions have usually been based on arbitrary percentage reductions in seizure frequency measured over unspecified intervals of follow up with no indication of preoperative condition.

In analysing outcome on seizure control the use of actuarial statistics, measuring time to one or more years remission, has much to recommend it. The method can be easily applied as only two variables are needed, time to onset of first remission and duration of follow up. These data can be reliably and objectively obtained for each patient leading to a uniformity in reporting results. The results given in actuarial curves relate to the cumulative percentage of patients who have ever been in remission, based on the number of patients at risk. They therefore have the major advantage of taking account of variable follow up. This is particularly important when assessing the impact of prognostic variables as the patients who are in remission change throughout follow up. A prognostic variable associated with outcome at two years need not necessarily apply after 10 years of follow up. A further advantage of actuarial statistics is that the relative importance and possible interaction of prognostic variables can be readily evaluated. ${ }^{13}$ It is for these reasons that actuarial statistics have become increasingly used in recent years to assess outcome in epilepsy. They are the method of choice for analysing the prognosis for seizure control in epilepsy, ${ }^{14}{ }^{15}$ recurrence rates following a first seizure, ${ }^{16}$ relapse rates after drug withdrawal, ${ }^{17}$ and response to drug treatment in anticonvulsant trials involving prolonged follow up. ${ }^{18}$

The analysis of outcome considered here relates purely to seizure control. This is appropriate when assessing prognosis following resective surgery for temporal lobe epilepsy where the goal of treatment is complete abolition of all seizures in a patient with previously intractable drug resistant epilepsy. However, if palliative surgery is being used, for example corpus callosotomy, then other methods may be needed. Small changes in seizure frequency, clustering of attacks, the presence or absence of an aura, incontinence, injury or falling during fits and whether they occur diurnally or nocturnally, may all be important considerations for individual patients. In this instance assessment of quality of life, based on such measures as seizure severity, employment and financial or social independence may be more appropriate determinants of outcome.

1 Penfield $W$, Flanigin $W$. Surgery of temporal lobe seizures. Arch Neurol Psychiatry 1950;64:491-500.

2 Rasmussen T. Surgical treatment of patients with complex partial seizures. In: Penry JK, Daly DD, eds. Complex partial seizures and their treatment. Advances in neurology, Vol 11. New York: Raven Press, 1975:415-22.

3 Rasmussen TB. Surgical treatment of complex partial seizures: results, lessons and problems. Epilepsia seizures: results, lesson

4 Falconer MA, Serafetinides EA. A follow up study of surgery in temporal lobe epilepsy. $J$ Neurol Neurosurg Psychiatry 1963;26:154-65.

5 Green JR, Scheetz DG. Surgery of epileptogenic lesions of the temporal lobe. Arch Neurol 1964;10:135-48.

6 Van Buren JM, Ajmone-Marsan C, Mutsuga N, Sadowsky D. Surgery of temporal lobe epilepsy. In: Purpura DP Penry IK, Walter RD eds. Neurosurgical management of the epilepsies. Advances in neurology, Vol 8. New York: Raven Press, 1975:155-96.

7 Jensen I. Temporal lobe surgery around the world. Results, complications and mortality. Acta Neurol Scand 1975; 52:354-73.

8 Dodrill CB, Wilkus RJ, Ojemann GA, et al. Multidisciplinary prediction of seizure relief from cortical disciplinary prediction of seizure relief from
resection surgery. Ann Neurol 1986;20:2-12.

9 Bonis A. Long term results of cortical excisions based on stereotaxic investigations in severe drug resistant epilepsies. Acta Neurochir 1980;Suppl 30:55-66.

10 Engel J. Outcome with respect to seizures. In: Engel J, ed. Surgical treatment of the epilepsies. New York: Raven Press, 1988:553-71.

11 Kaplan EL, Meier P. Nonparametric estimations from incomplete observations. J Am Stat Assoc 1958;53: 457-81.

12 SSPS/PC + v3.0. SSPS Inc, Chicago, Illinois 1988.

13 Cox DR. Regression models and life tables. JR Stat Soc 1972;34:187-220.

14 Annegers JF, Hauser WA, Elveback LR. Remission of seizures and relapse in patients with epilepsy. Epilepsio 1979;20:729-37.

15 Elwes RDC, Johnson AL, Shorvon SD, Reynolds EH. The prognosis for seizure control in newly diagnosed epilepsy. N Engl J Med 1985;313:145-51.

16 Hauser WA, Anderson VE, Loewenson RB, McRoberts SM. Seizure recurrence after a first unprovoked seizure. $N$ Engl J Med 1982;307:522-8.

17 Chadwick D. The discontinuation of antiepileptic therapy. In: Pedley TA, Meldrum BS, eds. Recent advances in epilepsy, 2. Edinburgh: Churchill Livingstone, 1985: 111-24.

18 Mattson RH, Cramer JA, Collins JF, et al. Comparison of carbamazepine, phenobarbital, phenytoin and primidone in partial and secondary generalised epilepsy. $N$ Engl $J$ Med 1985;313:145-51. 